\title{
Absolute quantum yield measurements for the formation of oxygen atoms after UV laser excitation of $\mathrm{SO}_{2}$ at $222.4 \mathrm{~nm}$
}

\author{
MOHAMMED ABU-BAJEH ${ }^{\mathrm{a}}$, MELANIE CAMERON ${ }^{\mathrm{b}}$, \\ KYUNG-HOON JUNG ${ }^{\mathrm{c}}$, CHRISTOPH KAPPEL ${ }^{\mathrm{d}}$, ALMUTH LÄUTER $^{\mathrm{a}}$, \\ KYOUNG-SEOK LEE ${ }^{\mathrm{c}}$, HARI P UPADHYAYA ${ }^{\mathrm{e}}$, RAJESH K VATSA $^{\mathrm{e}}$ and \\ HANS-ROBERT VOLPP ${ }^{\mathrm{a} *}$ \\ ${ }^{a}$ Physikalisch-Chemisches Institut der Universität Heidelberg, Im \\ Neuenheimer Feld 253, D-69120 Heidelberg, Germany \\ ${ }^{\mathrm{b}}$ Max-Planck-Institut für Chemie, Division of Atmospheric Chemistry, \\ D-55020 Mainz, Germany \\ ${ }^{\mathrm{c}}$ Department of Chemistry and Molecular Science Institute (BK21), Korea \\ Advanced Institute of Science and Technology (KAIST), Yusung-Gu, \\ Taejon 305-701, Korea \\ ${ }^{\mathrm{d}}$ Institut für Physikalische Chemie der Universität Göttingen, D-37075 \\ Göttingen, Germany \\ ${ }^{\mathrm{e}}$ Chemistry and Isotope Group, Bhabha Atomic Research Center, \\ Mumbai 400 085, India \\ e-mail: aw2@ix.urz.uni-heidelberg.de
}

\begin{abstract}
The dynamics of formation of oxygen atoms after UV photoexcitation of $\mathrm{SO}_{2}$ in the gas-phase was studied by pulsed laser photolysis-laser-induced fluorescence 'pump-and-probe' technique in a flow reactor. $\mathrm{SO}_{2}$ at room-temperature was excited at the $\mathrm{KrCl}$ excimer laser wavelength $(222.4 \mathrm{~nm})$ and $\mathrm{O}\left({ }^{3} \mathrm{P}_{j}\right)$ photofragments were detected under collision-free conditions by vacuum ultraviolet laser-induced fluorescence. The use of narrow-band probe laser radiation, generated via resonant third-order sum-difference frequency conversion of dye laser radiation in Krypton, allowed the measurement of the nascent $\mathrm{O}\left({ }^{3} \mathrm{P}_{j=2,1,0}\right)$ fine-structure state distribution: $n_{j=2} / n_{j=1} / n_{j=0}=(0.88 \pm 0.02) /(0 \cdot 10 \pm 0 \cdot 01) /(0 \cdot 02 \pm 0 \cdot 01)$. Employing $\mathrm{NO}_{2}$ photolysis as a reference, a value of $\Phi_{\mathrm{O}\left({ }^{3} \mathrm{P}\right)}=0.13 \pm 0.05$ for the absolute $\mathrm{O}\left({ }^{3} \mathrm{P}\right)$ atom quantum yield was determined. The measured $\mathrm{O}\left({ }^{3} \mathrm{P}\right)$ quantum yield is compared with the results of earlier fluorescence quantum yield measurements. A suitable mechanism is suggested in which the dissociation proceeds via internal conversion from high rotational states of the initially excited $\mathrm{SO}_{2}\left(\widetilde{C}^{1} \mathrm{~B}_{2}\right)(1,2,2)$ vibronic level to nearby continuum states of the electronic ground state.
\end{abstract}

Keywords. Sulphur dioxide; photodissociation dynamics; oxygen atom;VUV-LIF; quantum yield.

\section{Introduction}

Direct emission of sulphur dioxide, $\mathrm{SO}_{2}$, from anthropogenic activities such as coal combustion in power plants, is the largest individual source of sulphur in the earth's troposphere. ${ }^{1}$ Due to its importance as a combustion and atmospheric trace species the thermal decomposition kinetics and photochemistry of $\mathrm{SO}_{2}$ have been studied for many

\footnotetext{
*For correspondence
} 
years. ${ }^{2,3}$ Earlier spectroscopic and photochemical results obtained in the wavelength region $105-390 \mathrm{~nm}$ were reviewed in great detail by Okabe. ${ }^{4}$ Most recent work has focused on the high-resolution spectroscopic characterisation of the $\mathrm{SO}_{2}$ vibronic bands in the wavelength range $292-329 \mathrm{~nm}$ and the state-resolved dissociation dynamics of $\mathrm{SO}_{2}$ following laser photoexcitation in the structured electronic absorption band in the 180$235 \mathrm{~nm}$ region. ${ }^{5,6}$ The latter band has been assigned to an optical transition from the $\tilde{X}^{1} \mathrm{~A}_{1}$ ground state of $\mathrm{SO}_{2}$ to the third excited singlet state, $\tilde{C}^{1} \mathrm{~B}_{2}$, located $42573 \mathrm{~cm}^{-1}$ above the ground state. ${ }^{7}$ which can lead to the formation of $\operatorname{SO}\left(X^{3} \Sigma^{-}\right)$and $\left.\mathrm{O}^{3} \mathrm{P}\right)$ photofragments via a predissociation mechanism. ${ }^{8}$

A number of studies have been carried out in which the products from the $\mathrm{SO}_{2}$ dissociation after photoexcitation at the ArF excimer laser wavelength $(193.3 \mathrm{~nm})$ were detected employing different spectroscopic methods. ${ }^{9-18}$ The first study of the dynamics of this process was carried out by Freedman et al, who applied the molecular beam photofragment time-of-flight (TOF) technique to determine the translational energy distribution of the SO fragments. ${ }^{9}$ Based on their measured translational energy distribution they concluded that the majority of the SO products should be produced in the $v^{\prime \prime}=3$ and $v^{\prime \prime}=4$ vibrational states. These experiments were later repeated by Kawasaki et $\mathrm{al}^{10}$ with a pulsed molecular beam source. In these experiments the angular distribution of the SO fragments was measured and found to be isotropic. In a subsequent study Kawasaki et $\mathrm{al}^{11}$ measured the $\mathrm{O}$ atom TOF distribution from which they derived a SO vibrational state distribution with a maximum at $v^{\prime \prime}=2$. In a reinvestigation of the SO product translational energy release with a high-resolution molecular beam photofragment TOF apparatus, Felder $e t \mathrm{al}^{12,13}$ obtained a SO vibrational state distribution which was found to be in good agreement with the distribution measured by Kanamori et al in the gas-phase photodissociation study using diode laser spectroscopy for SO detection. ${ }^{14}$ The latter SO vibrational distributions, however, were found to be more sharply peaked at $v^{\prime \prime}=2$ than the earlier one reported in ref. [11]. Experiments in which $\operatorname{SO}\left(X^{3} \Sigma^{-}\right)$products were detected by laser-induced fluorescence (LIF) and molecular beam-Fourier transform microwave spectroscopy were reported in refs. [15] and [16] respectively. So far two gasphase photolysis studies of $\mathrm{SO}_{2}$ at $193.3 \mathrm{~nm}$ have been reported in which dynamics of the formation of $\mathrm{O}\left({ }^{3} \mathrm{P}\right)$ atom was investigated by LIF spectroscopy. ${ }^{17,18}$ However, markedly different $\mathrm{O}\left(+3 \mathrm{P}_{j}=2,1,0\right)$ fine-structure state distributions were obtained in the latter studies which do not agree within their uncertainty limits.

Several experiments were performed to investigate the fragmentation mechanism at lower excitation energies near the onset of predissociation. ${ }^{4,19-24}$ Okabe was the first who measured absorption and fluorescence excitation spectra of the $\widetilde{C}^{1} \mathrm{~B}_{2} \leftarrow \widetilde{X}^{1} \mathrm{~A}_{1}$-system of gas-phase $\mathrm{SO}_{2}$ at room temperature in the wavelength region $200-235 \mathrm{~nm}{ }^{19}$. He attributed the sudden decrease of the fluorescence yield observed near $219 \mathrm{~nm}$ to the onset of predissociation. Later, fluorescence lifetime and absolute fluorescence quantum yield measurements from single vibronic states in the $210-230 \mathrm{~nm}$ absorption region of room-temperature $\mathrm{SO}_{2}$ were performed by Hui and Rice. ${ }^{20}$ In these studies a sharp drop in fluorescence lifetime and quantum yield was observed for wavelengths shorter than $220.6 \mathrm{~nm}$. The results of subsequent predissociation threshold measurements by Ebata $e t$ $a l,{ }^{21}$ Kanamori et $a l,{ }^{14}$ and Ivanco $e t a l^{22}$ are discussed in detail by Becker $e t a l^{23,24}$ who investigated the dissociation of supersonic jet cooled $\mathrm{SO}_{2}$ from selected single rovibrational levels of the $\tilde{C}^{1} \mathrm{~B}_{2}$ state. In these experiments the use of resonant enhanced multiphoton ionization (REMPI) TOF product detection allowed the measurement of all electronic and rovibrational quantum numbers of the $\mathrm{O}$ and $\mathrm{SO}$ fragments respectively, at 
excitation energies near the $\mathrm{SO}_{2}\left(\tilde{C}^{1} \mathrm{~B}_{2}\right) \rightarrow \mathrm{SO}\left(X^{3} \Sigma^{-} ; v^{\prime \prime}=0\right)+\mathrm{O}\left({ }^{3} \mathrm{P}_{j=2}\right)$ predissociation threshold ${ }^{23}$. Despite a large number of studies on the product-state resolved dissociation dynamics, to the best of our knowledge, no absolute product yields have been reported so far. In the present work, we measured the absolute quantum yield for $\mathrm{O}\left({ }^{3} \mathrm{P}\right)$ product formation after photoexcitation at the $\mathrm{KrCl}$ excimer laser wavelength $(222.4 \mathrm{~nm})$. The use of this wavelength allows selective excitation of the $(1,2,2)$ vibronic band of the $\mathrm{SO}_{2}\left(\tilde{C}^{1} \mathrm{~B}_{2}\right)$ state, where the three numbers in parentheses, $\left(\mathbf{v}_{1}^{\prime}, v_{2}^{\prime}, v_{3}^{\prime}\right)$, represent the vibrational quantum numbers of the symmetric stretch, the bend, and the anti-symmetric stretch normal-modes, respectively. ${ }^{8}$ Our investigations are therefore complementary to the studies of Hui and Rice who determined absolute fluorescence quantum yields, $\Phi_{f}$, by calibrating their relative measurements against the known fluorescence quantum yield of benzene. ${ }^{20}$

\section{Experimental}

Photodissociation studies were carried out in a flow reactor employing a pulsed laser pump-probe setup which was recently modified to allow VUV-LIF detection of $\left.\mathrm{O}^{3} \mathrm{P}\right)$ atoms. ${ }^{25} \mathrm{~A}$ detailed description of the experimental setup has been given elsewhere. ${ }^{26}$ Hence, only a brief summary of the experimental method will be given in the following.

$\mathrm{SO}_{2}$ (Messer Griesheim, purity $>99.98 \%$ ) was pumped through the flow reactor at room temperature. The $\mathrm{SO}_{2}$ pressure in the cell was typically $30-55 \mathrm{mTorr}$ (monitored by an MKS Baratron gauge). For photolytic calibration measurements, $\mathrm{NO}_{2}$ (Messer Griesheim, purity $>99.98 \%$ ) was passed through the cell at pressures of typically 1030 mTorr. Gas flows were maintained at high enough rates to ensure gas renewal between successive laser shots at a laser repetition rate of $6 \mathrm{~Hz}$.

An excimer laser (Lambda Physik EMG 102 MSC) operating at the $\mathrm{KrCl}$ emission wavelength $\left(222.4 \mathrm{~nm}^{27}\right)$ optimised for broadband operation with a spectral bandwidth of $80 \mathrm{~cm}^{-1}(\sim 0.4 \mathrm{~nm})^{28}$ and a pulse duration of $15-20 \mathrm{~ns}$ was used to photodissociate the $\mathrm{SO}_{2}$ as well as the $\mathrm{NO}_{2}$ molecules (used in the calibration measurements). Pump laser intensities were in the range $1-3 \mathrm{~mJ} / \mathrm{cm}^{2}$. Photolysis studies of $\mathrm{SO}_{2}$ at $193.3 \mathrm{~nm}$ were performed with a Lambda Physik LPX $205 \mathrm{ArF}$ excimer laser with a spectral bandwidth of $190 \mathrm{~cm}^{-1}(\sim 0.7 \mathrm{~nm})$ at laser intensities of typically $0.5-1 \mathrm{~mJ} / \mathrm{cm}^{2}$ and $2 \mathrm{mTorr}^{2} \mathrm{SO}_{2}$ pressure.

For VUV-LIF detection of $\mathrm{O}\left({ }^{3} \mathrm{P}_{j}\right)$ atoms via the three allowed $\mathrm{O}\left(3 s{ }^{3} \mathrm{~S}^{\circ} \leftarrow 2 p^{3} \mathrm{P}_{j}\right)$ transitions, ${ }^{29}$ narrow-band (bandwidth $\sim 0.45 \mathrm{~cm}^{-1}$ ) pulsed probe laser radiation (pulse duration $10-15 \mathrm{~ns}$ ), tuneable in the wavelength region $130 \cdot 2-130 \cdot 7 \mathrm{~nm}$ was generated by sum-difference frequency conversion of dye laser radiation in Krypton. The generated VUV laser beam was separated from the unconverted laser radiation and aligned to overlap the pump beam at right angles in the viewing region of a LIF detector. The delay time between the pump and probe pulses was typically $250 \mathrm{~ns}$, to allow collision-free detection of the nascent $\mathrm{O}\left({ }^{3} \mathrm{P}_{j}\right)$ fragments. Under these experimental conditions fly-out of $\mathrm{O}\left({ }^{3} \mathrm{P}\right)$ atoms, intramultiplet relaxation of the spin-orbit excited states $\mathrm{O}\left({ }^{3} \mathrm{P}_{j=1,0}\right)$ by quenching and secondary reactions with $\mathrm{SO}_{2}$ and $\mathrm{NO}_{2}$, respectively, were negligible.

LIF was observed via a solar blind photomultiplier (THORN EMI model 9413 B) positioned at right angles to both pump and probe laser beams. The VUV probe beam intensity was monitored after passing through the reaction cell by an additional photomultiplier. For the subtraction of 'background' $\left.\mathrm{O}^{3} \mathrm{P}_{j}\right)$ atom signal generated by VUV 
probe beam photolysis an electronically controlled mechanical shutter was inserted into the photolysis beam path, such that at each point of the $\mathrm{O}\left({ }^{3} \mathrm{P}_{j=2,1,0}\right)$ spectra, the signal could first be averaged 30 times with the shutter opened and again averaged 30 times with the shutter closed. Finally, a point-by-point subtraction procedure was adopted, to obtain directly and on-line a LIF signal representing the contribution from $\mathrm{O}\left({ }^{3} \mathrm{P}_{j=2,1,0}\right)$ atoms generated solely by the pump laser pulse. VUV probe and pump laser intensities were monitored and the LIF signal was normalised to both laser intensities. In the experiments care was taken that the $\mathrm{O}\left({ }^{3} \mathrm{P}_{j}\right)$ atom signals showed a linear dependence on the pump laser intensity. Figure 1 depicts results of such a linearity check which clearly confirms that the detected products originate from a one-photon dissociation process.

Experiments were also performed to measure the quantum yield of $\mathrm{O}\left({ }^{1} \mathrm{D}\right)$ in the photodissociation of $\mathrm{NO}_{2}$ by making use of the fast reaction $\mathrm{O}\left({ }^{1} \mathrm{D}\right)+\mathrm{H}_{2} \rightarrow \mathrm{OH}+\mathrm{H}$. The nascent $\mathrm{H}$ atoms produced from the reaction were detected by the VUV-LIF using the Lyman $\alpha \quad 6 \mathrm{~nm}$. For this purpose, narrow band VUV laser light tunable around the $\mathrm{H}$ atom Lyman $\alpha$ transition was generated by resonant third-order sumdifference frequency conversion of pulsed dye laser radiation in a phase-matched $\mathrm{Kr}-\mathrm{Ar}$ mixture. ${ }^{26}$ In the $\mathrm{Kr}$ four-wave mixing scheme $\left(\omega_{\mathrm{VV}}=2 \times \omega_{R}-\omega_{r}\right)$ via which the VUV radiation was generated, the laser radiation of $\lambda_{R}=212.55 \mathrm{~nm}$ is two-photon resonant with the $\operatorname{Kr}(4 p-5 p)[1 / 2,0]$ transition and held fixed during the experiments, while $\omega_{r}$ could be tuned from 844 to $846 \mathrm{~nm}$ to generate the VUV laser radiation covering the $\mathrm{H}$ atom Lyman- $\alpha$ transition. The fundamental laser radiation was obtained from two dye lasers simultaneously pumped by a $\mathrm{XeCl}$ excimer laser. In the first dye laser, coumarin 120 was used to generate the $425.1 \mathrm{~nm}$ radiation which was subsequently frequency doubled in a BBO crystal in order to obtain $\lambda_{R}=212.55 \mathrm{~nm}$. $\lambda_{T}=844-846 \mathrm{~nm}$ was obtained by operating the second laser with Styryl 9 dye. The generated Lyman- $\alpha$ was carefully separated from the fundamental laser light by a lens monochromator followed by a light baffle system. A bandwidth of $\Delta \omega_{\mathrm{UV}} \approx 0.4 \mathrm{~cm}^{-1}$ was determined for the Lyman- $\alpha$ laser radiation in separate experiments by measuring $\mathrm{H}$-atom Doppler profiles under thermalised conditions.

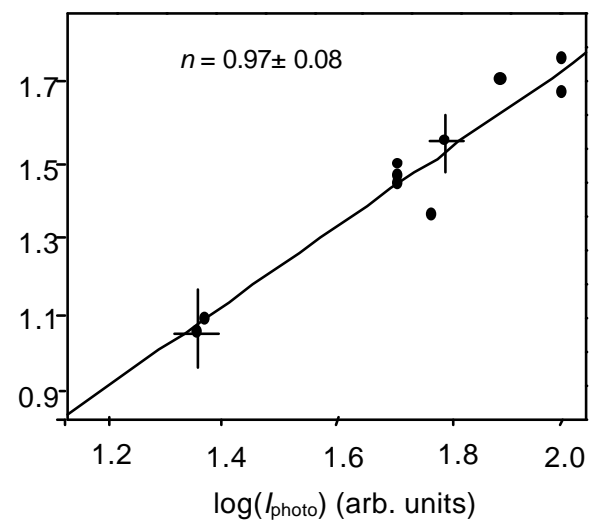

Figure 1. Dependence of the observed $\mathrm{O}\left({ }^{3} \mathrm{P}_{j=2}\right)$ atomLIF signal from $\mathrm{SO}_{2}$ photolysis on the $(222.4 \mathrm{~nm})$ photolysis laser intensity $\left(I_{\text {photo }}\right)$. The slope $n$ of the fitted linear $\log -\log$ plot is given in the figure. 


\section{Results}

\section{$3.1 O\left({ }^{3} P\right)$ fine-structure state distribution}

Figure 2 shows typical Doppler profiles of $\mathrm{O}\left({ }^{3} \mathrm{P}_{j=2,1,0}\right)$ atoms produced in the gas-phase dissociation of $\mathrm{SO}_{2}$ at room-temperature after excitation at $222.4 \mathrm{~nm}$. The fine-structure state distribution of the $\mathrm{O}\left({ }^{3} \mathrm{P}_{j=2,1,0}\right)$ fragments was determined from the integrated areas of the Doppler profiles after correcting for the slightly different oscillator strengths of the spectral transitions used in probing the different $j$-states. ${ }^{29}$ Fine-structure state distributions were repeatedly measured at pump-probe delay times between 100 and $350 \mathrm{~ns}$ and at different $\mathrm{SO}_{2}$ pressures in the range 30-55 mTorr. No significant differences in the distributions were observed under these experimental conditions. An evaluation of 40 Doppler profiles yielded the nascent population distribution $n_{j=2} / n_{j=1} / n_{j=0}=(0 \cdot 88 \pm 0 \cdot 02) /$ $(0.10 \pm 0.01) /(0.02 \pm 0.01)$ for $j=2$ (ground state), $j=1 \quad\left(158.26 \mathrm{~cm}^{-1}\right)$ and $j=0$ $\left(226.98 \mathrm{~cm}^{-1}\right)$ where the errors represent the $1 \sigma$ statistical uncertainties of the experimental data. This distribution deviates significantly from the $n_{j=2} / n_{j=1} / n_{j=0}=(0.592 \pm$ $0.05) /(0.295 \pm 0.032) /(0 \cdot 114 \pm 0.033)$ distribution reported for the $193.3 \mathrm{~nm}$ laser photolysis of $\mathrm{SO}_{2}$ in ref. [17]. The latter is close to a statistical 'prior' distribution, $n_{j=2} / n_{j=1} /$ $n_{j=0}=0 \cdot 56 / 0 \cdot 33 / 0 \cdot 11$, which is determined (in the limit of large excess energies) by the ratios of the $(2 j+1)$-degeneracies of the $\mathrm{O}\left({ }^{3} \mathrm{P}_{j}\right)$ fine-structure states. ${ }^{30}$ However, in view of the discrepancy between the $\mathrm{O}\left({ }^{3} \mathrm{P}_{j=2,1,0}\right)$ fine-structure state distributions obtained in refs. [17, 18] after $193 \cdot 3 \mathrm{~nm}$ excitation of $\mathrm{SO}_{2}$ we also remeasured the $\mathrm{O}\left({ }^{3} \mathrm{P}_{j=2,1,0}\right)$ finestructure state distribution at that particular photolysis wavelength and obtained a clearly non-statistical distribution, $n_{j=2} / n_{j=1} / n_{j=0}=(0 \cdot 70 \pm 0 \cdot 01) /(0 \cdot 21 \pm 0 \cdot 01) /(0 \cdot 09 \pm 0.01)$, which is (within the combined error bars) in very good agreement with the distribution obtained by Kawasaki and co-workers. ${ }^{18}$

\subsection{Absolute $\mathrm{O}\left({ }^{3} \mathrm{P}\right)$ atom product quantum yield in the $222.4 \mathrm{~nm}$ photolysis of $\mathrm{SO}_{2}$}

After having measured the $\mathrm{O}\left({ }^{3} \mathrm{P}_{j}\right)$ distribution, the absolute primary product quantum yield, $\Phi_{\mathrm{O}\left({ }^{3} \mathrm{P}\right)}$, for $\mathrm{O}\left({ }^{3} \mathrm{P}\right)$ formation in the $222.4 \mathrm{~nm}$ photolysis of $\mathrm{SO}_{2}$ was obtained by

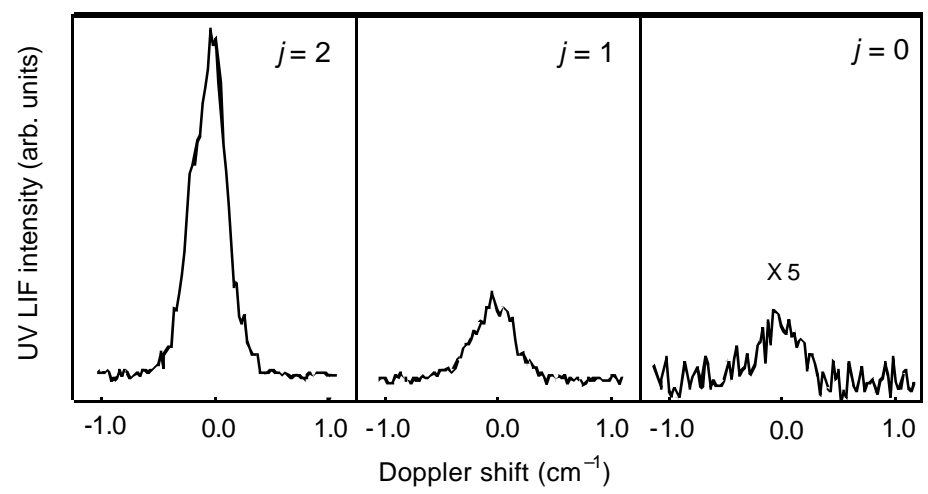

Figure 2. Vacuum ultraviolet LIF spectra of the $\mathrm{O}\left({ }^{3} \mathrm{P}_{j=2,1,0}\right)$ atom products recorded $250 \mathrm{~ns}$ after pulsed $(222 \cdot 4 \mathrm{~nm})$ excimer laser photolysis of $50 \mathrm{mTorr}$ of $\mathrm{SO}_{2}$. Line centers correspond to the $\left(3 s^{3} \mathrm{~S}^{\circ} \leftarrow 2 p^{3} \mathrm{P}_{j}\right)$-transition of the $\mathrm{O}\left({ }^{3} \mathrm{P}_{j=2}\right), \mathrm{O}\left({ }^{3} \mathrm{P}_{j=1}\right)$ and $\mathrm{O}\left({ }^{3} \mathrm{P}_{j=0}\right)$ atom fragments at $76794.98 \mathrm{~cm}^{-1}, 76636.72 \mathrm{~cm}^{-1}$ and $76568.00 \mathrm{~cm}^{-1}$ respectively. 
calibrating the $\mathrm{O}\left({ }^{3} \mathrm{P}_{j=2}\right)$ signal, $\mathrm{S}_{j=2}\left(\mathrm{SO}_{2}\right)$, measured in the $\mathrm{SO}_{2}$ photodissociation against the $\mathrm{O}\left({ }^{3} \mathrm{P}_{j=2}\right)$ signal, $\mathrm{S}_{j=2}\left(\mathrm{NO}_{2}\right)$, observed in the $\mathrm{NO}_{2}$ photolysis at the same wavelength (see figure 3 ). Because the photolysis experiments were carried out under optically thin conditions - with only a few percent of the parent molecules being dissociated - and at identical photolysis laser intensities, the following relationship could be used in the evaluation of $\Phi_{\mathrm{O}\left({ }^{3} \mathrm{P}\right)}$ :

$$
\begin{aligned}
\Phi_{\mathrm{O}\left({ }^{3} \mathrm{P}\right)}= & \left\{\mathrm{S}_{j=2}\left(\mathrm{SO}_{2}\right) \phi_{\mathrm{O}\left({ }^{3} \mathrm{P}\right)}\left(\mathrm{NO}_{2}\right) N_{j=2}\left(\mathrm{NO}_{2}\right) \sigma_{\mathrm{NO}_{2}} \mathrm{p}_{\mathrm{NO}_{2}}\right\} / \\
& \left\{\mathrm{S}_{j=2}\left(\mathrm{NO}_{2}\right) n_{j=2}\left(\mathrm{SO}_{2}\right) \sigma_{\mathrm{SO}_{2}} \mathrm{p}_{\mathrm{SO}_{2}}\right\},
\end{aligned}
$$

where $\sigma_{\mathrm{NO}_{2}}$ and $\sigma_{\mathrm{SO}_{2}}$ are the room-temperature absorption cross-sections of $\mathrm{NO}_{2}$ and $\mathrm{SO}_{2}$ at $222.4 \mathrm{~nm}$ and $\mathrm{p}_{\mathrm{NO}_{2}}$ and $\mathrm{p}_{\mathrm{SO}_{2}}$ are the $\mathrm{NO}_{2}$ and $\mathrm{SO}_{2}$ pressures, respectively. The absorption cross sections $\sigma_{\mathrm{NO}_{2}}=(4 \cdot 2 \pm 0.2) \times 10^{-19} \mathrm{~cm}^{2}$ and $\sigma_{\mathrm{SO}_{2}}=(1 \cdot 1 \pm 0 \cdot 2) \times 10^{-18} \mathrm{~cm}^{2}$ were obtained from the data given in ref. [31] respectively, taking into account the actual

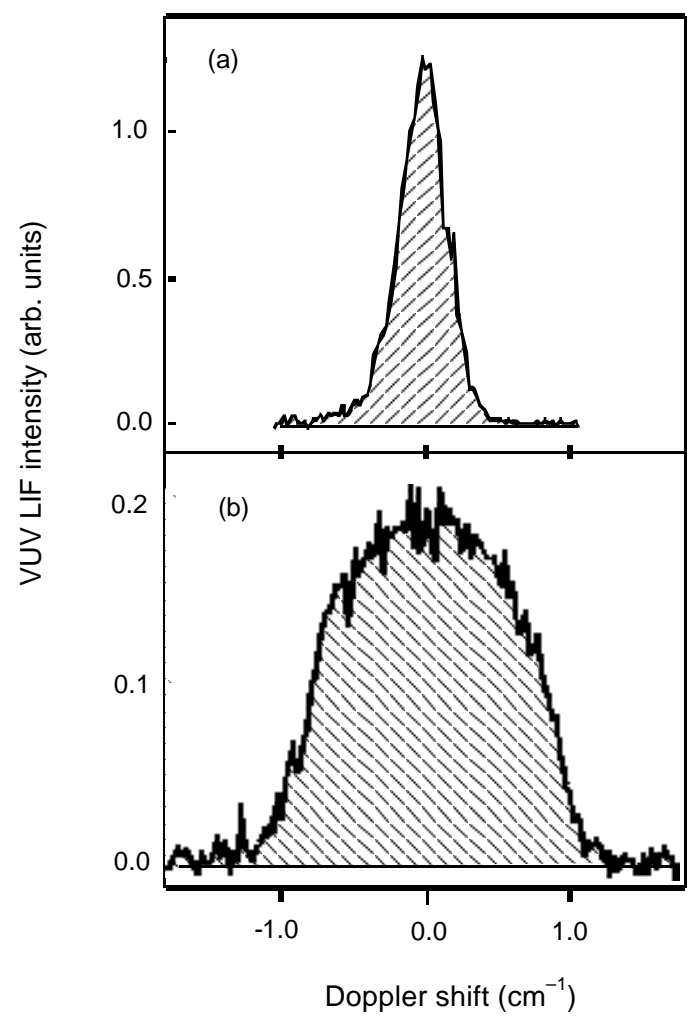

Figure 3. Comparison of Doppler profiles of $\mathrm{O}\left({ }^{3} \mathrm{P}_{j=2}\right)$ atoms produced in the $\mathrm{KrCl}$ $\left(222.4 \mathrm{~nm}\right.$ ) excimer laser photolysis of (a) $50 \mathrm{mT}$ orr of $\mathrm{SO}_{2}$ and (b) $29 \mathrm{mTorr} \mathrm{NO}_{2}$. Spectra were recorded $250 \mathrm{~ns}$ after the photolysis laser pulse. Line centers correspond to the $\left(3 s{ }^{3} \mathrm{~S}^{\circ} \leftarrow 2 p{ }^{3} \mathrm{P}_{j}\right)$-transition of the $\mathrm{O}\left({ }^{3} \mathrm{P}_{j=2}\right)$ atoms $\left(76794.98 \mathrm{~cm}^{-1}\right)$. Details about the photolytic calibration procedure for the measurement of the absolute $\mathrm{O}\left({ }^{3} \mathrm{P}\right)$ atom quantum yield are given in the text. 
photolysis laser bandwidth. $\mathrm{N}_{j=2}\left(\mathrm{NO}_{2}\right)$ and $n_{j=2}\left(\mathrm{SO}_{2}\right)$ are the relative populations of the respective $\mathrm{O}\left({ }^{3} \mathrm{P}_{j=2}\right)$ states. The value $n_{j=2}\left(\mathrm{SO}_{2}\right)=(0 \cdot 88 \pm 0.02)$ could be taken from the measured fine-structure distribution given above. The UV photodissociation dynamics of $\mathrm{NO}_{2}$ has been investigated in great detail (see, for example refs. [32-35], and references therein) but the nascent $\mathrm{O}\left({ }^{3} \mathrm{P}_{j}\right)$ fine-structure distribution for the $222.4 \mathrm{~nm}$ photolysis wavelength has not been reported so far. It was therefore measured in the present study and the following result, $N_{j=2} / N_{j=1} / N_{j=0}\left(\mathrm{NO}_{2}\right)=(0.52 \pm 0.03) /(0.33 \pm 0.01) /(0.15 \pm 0.02)$, was obtained, which is in good agreement with the $\mathrm{O}\left({ }^{3} \mathrm{P}_{j}\right)$ fine-structure distribution obtained by Zare and co-workers for the $226 \mathrm{~nm}$ photolysis wavelength. ${ }^{34}$

The product branching into $\mathrm{N}+\mathrm{O}_{2}$, and $\mathrm{O}\left({ }^{1} \mathrm{D}\right)+\mathrm{NO}$ in the $228.8 \mathrm{~nm}$ photolysis of $\mathrm{NO}_{2}$ was studied by Preston and Cvetanovic. ${ }^{36}$ They demonstrated that $\mathrm{N}$ atom formation is unimportant and reported a value of 0.4 for the primary $\mathrm{O}\left({ }^{1} \mathrm{D}\right)$ quantum yield. Later on, Uselman and $\mathrm{Lee}^{37}$ measured $\mathrm{O}\left({ }^{1} \mathrm{D}\right)$ quantum yields in the $\mathrm{NO}_{2}$ photodissociation at different wavelengths in the region 248 to $213.9 \mathrm{~nm}$. From their results, a value of $\phi_{O}\left({ }^{1}\right)\left(\mathrm{NO}_{2}\right)=0.44$ for the $222.4 \mathrm{~nm}$ wavelength can be obtained using the best fit to the data points. With this value the quantum yield for $\mathrm{O}\left({ }^{3} \mathrm{P}\right)$ formation could be calculated to be $\phi_{\mathrm{O}\left({ }^{3} \mathrm{P}\right)}\left(\mathrm{NO}_{2}\right)=1-\phi_{\mathrm{O}\left({ }^{1} \mathrm{D}\right)}\left(\mathrm{NO}_{2}\right)=0.56$. However, it is desirable to have an independent experimentally measured quantum yield value for $\mathrm{O}\left({ }^{1} \mathrm{D}\right)$ at this wavelength. We used two different approaches for this purpose which are described below. In the first approach, the $\mathrm{O}\left({ }^{1} \mathrm{D}\right)$ quantum yield of $\mathrm{NO}_{2}$ was measured making use of the fast reaction $\mathrm{O}\left({ }^{1} \mathrm{D}\right)+$ $\mathrm{H}_{2} \rightarrow \mathrm{H}+\mathrm{OH}$, we observed the time evolution of the $\mathrm{H}$ atom products via LIF at the $\mathrm{H}$ atom Lyman- $\alpha$ wavelength $(121.6 \mathrm{~nm})$. Figure 4 shows the temporal evolution of $\mathrm{H}$ atoms produced in the reaction $\mathrm{O}\left({ }^{1} \mathrm{D}\right)+\mathrm{H}_{2} \rightarrow \mathrm{H}+\mathrm{OH}$ followed by the decay due to the $\mathrm{H}+\mathrm{NO}_{2} \rightarrow \mathrm{OH}+\mathrm{NO}$ reaction. The production and decay of $\mathrm{H}$ atoms as a function of

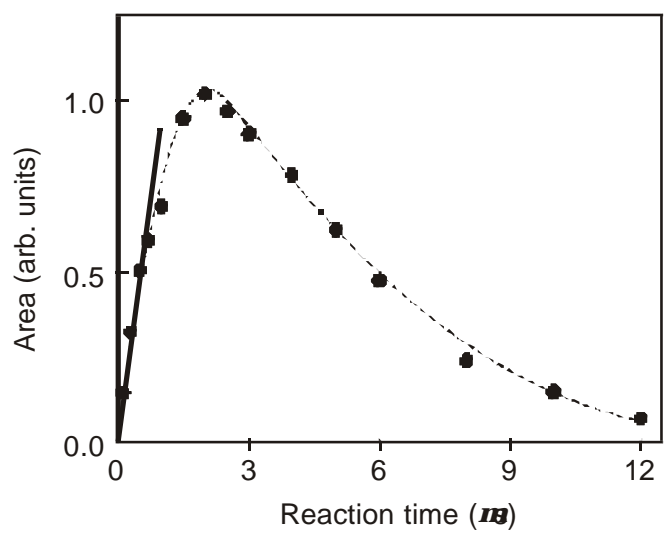

Figure 4. Temporal rise and decay of $\mathrm{H}$ atoms formed in the reaction of $\mathrm{O}\left({ }^{1} \mathrm{D}\right)$ atoms with $\mathrm{H}_{2} . \mathrm{O}\left({ }^{1} \mathrm{D}\right)$ atoms were produced by $222.4 \mathrm{~nm}$ photolysis of $\mathrm{NO}_{2}$ in the presence of $\mathrm{H}_{2}$ and $\mathrm{He}$. $\left(\mathrm{NO}_{2}\right.$ pressure $31 \mathrm{mTorr}, \mathrm{H}_{2}$ pressure $50 \mathrm{mTorr}$ and rest $\mathrm{He}$, total pressure $950 \mathrm{mTorr})$. $\mathrm{H}$ atoms were monitored via laser induced fluorescence (LIF) at the Lyman- $\alpha$ wavelength $(121.6 \mathrm{~nm})$. Straight line passing through the first three points indicates the region where linear approximation for the evaluation of the $\mathrm{O}\left({ }^{1} \mathrm{D}\right)$ quantum yield in the 222.4 photolysis of $\mathrm{NO}_{2}$ was used (see text for details). The dashed line shows the modelling of the curve using known rate constants from NIST data base. 
time was modelled taking into account the following reactions and rate constants (given in units of $\mathrm{cm}^{3}$ molecule $\mathrm{s}^{-1}$ ):

$$
\begin{array}{ll}
\mathrm{O}\left({ }^{1} \mathrm{D}\right)+\mathrm{H}_{2} \rightarrow \mathrm{H}+\mathrm{OH}, & k_{2}=2.7 \times 10^{-10}, \\
\mathrm{O}\left({ }^{1} \mathrm{D}\right)+\mathrm{NO}_{2} \rightarrow \mathrm{O}_{2}+\mathrm{NO}, & k_{3}=1.5 \times 10^{-10}, \\
\mathrm{H}+\mathrm{NO}_{2} \rightarrow \mathrm{OH}+\mathrm{NO}, & k_{4}=1.3 \times 10^{-10}, \\
\mathrm{O}\left({ }^{3} \mathrm{P}\right)+\mathrm{H}_{2} \rightarrow \mathrm{OH}+\mathrm{H}, & k_{5}=8.5 \times 10^{-18}, \\
\mathrm{O}\left({ }^{3} \mathrm{P}\right)+\mathrm{NO}_{2} \rightarrow \mathrm{O}_{2}+\mathrm{NO} . & k_{6}=9.7 \times 10^{-12} .
\end{array}
$$

It must be noted here that the reaction of translationally hot $\mathrm{O}\left({ }^{3} \mathrm{P}\right)$ atoms with $\mathrm{H}_{2}$ can also produce $\mathrm{H}$ atoms. With rate constants for the reactions taken from ref. [38] and the pressures of different reactants, the dashed curve in figure 4 was obtained. For determination of the $O\left({ }^{1} \mathrm{D}\right)$ quantum yield, a more simplified approach was used. The left part of the curve (small delay times up to $500 \mathrm{~ns}$ ) can be approximated by a linear curve. In this region, the increase of $\mathrm{H}$ atom concentration is only dependent on the delay time assuming $\left[\mathrm{H}_{2}\right]_{(t)} \approx\left[\mathrm{H}_{2}\right]_{(t=0)}$ and $\left[\mathrm{O}\left({ }^{1} \mathrm{D}\right)\right]_{(t)} \approx\left[\mathrm{O}\left({ }^{1} \mathrm{D}\right)\right]_{(t=0)}$. The absolute quantum yield can be derived from the integrated area of the Doppler profile by a photolytic calibration approach employing $\mathrm{H}_{2} \mathrm{~S}$ photolysis at $222.4 \mathrm{~nm}$ as a reference. ${ }^{39}$ Figure 5a shows a $\mathrm{H}$ atom Doppler profile from the $\mathrm{O}\left({ }^{1} \mathrm{D}\right)+\mathrm{H}_{2} \rightarrow \mathrm{H}+\mathrm{OH}$ reaction measured at a delay time of $300 \mathrm{~ns}$. A 'calibration H atom Doppler profile' obtained in the $222.4 \mathrm{~nm}$ photolysis of $\mathrm{H}_{2} \mathrm{~S}$ is shown in figure $5 \mathrm{~b}$. The following equation was used to calculate the absolute quantum yield of $\mathrm{O}\left({ }^{1} \mathrm{D}\right)$ :

$$
\begin{aligned}
\phi \mathrm{O}\left({ }^{1} \mathrm{D}\right) & \left.\mathrm{NO}_{2}\right)=\left\{S_{\mathrm{H}} \text { (reaction) } \sigma_{\mathrm{H}_{2} \mathrm{~S}}\left[\mathrm{H}_{2} \mathrm{~S}\right] \Phi_{\mathrm{H}}\left(\mathrm{H}_{2} \mathrm{~S}\right)\right\} / \\
& \left\{S_{\mathrm{H}}\left(\mathrm{H}_{2} \mathrm{~S} \text {-calibration }\right) \sigma_{\mathrm{NO}_{2}}\left[\mathrm{NO}_{2}\right]\left[\mathrm{H}_{2}\right] k_{2} t\right\},
\end{aligned}
$$

where $S_{\mathrm{H}}$ denotes the integrated area of the respective $\mathrm{H}$ atom Doppler profile, $\sigma_{\mathrm{H}_{2} \mathrm{~S}}$ and $\sigma_{\mathrm{NO}_{2}}$ are the optical absorption cross section of $\mathrm{H}_{2} \mathrm{~S}$ and $\mathrm{NO}_{2}$ at the $222.4 \mathrm{~nm}$ photolysis wavelength, $k_{2}$ is the rate constant for $\mathrm{H}$ atom production by the reaction of $\mathrm{O}\left({ }^{1} \mathrm{D}\right)$ with $\mathrm{H}_{2}, t$ is the pump-probe delay time at which the $\mathrm{H}$ atom products were detected, $\left[\mathrm{H}_{2} \mathrm{~S}\right]$, $\left[\mathrm{NO}_{2}\right]$, and $\left[\mathrm{H}_{2}\right]$ are the concentrations of $\mathrm{H}_{2} \mathrm{~S}, \mathrm{NO}_{2}$, and $\mathrm{H}_{2}$. The ratio of the optical absorption cross-sections $\sigma_{\mathrm{H}_{2} \mathrm{~S}} / \sigma_{\mathrm{NO}_{2}}$ at $222.4 \mathrm{~nm}$ was determined in independent measurements to be $1.96 \pm 0.20$. The $\mathrm{H}$ atom quantum yield in the $\mathrm{H}_{2} \mathrm{~S}$ photolysis at $222.4 \mathrm{~nm}$ is unity: $\Phi_{\mathrm{H}}\left(\mathrm{H}_{2} \mathrm{~S}\right)=1$. The rate constant $k_{2}$ for reaction of translationally excited $\mathrm{O}\left({ }^{1} \mathrm{D}\right)$ atoms with $\mathrm{H}_{2}$ which produces $\mathrm{H}$ atoms was studied earlier and the value of $k_{2}=(2.7 \pm$ $0.6) \times 10^{-10} \mathrm{~cm}^{3} / \mathrm{s}$ was determined. ${ }^{40}$ Using this method, evaluation of the first three data points in figure 4 (up to $t=500 \mathrm{~ns}$ ) yields an absolute quantum yield of $\phi_{0}\left({ }^{1} \mathrm{D}\right)\left(\mathrm{NO}_{2}\right)=$ $0.45 \pm 0.06$. The quoted error was calculated applying simple error propagation.

From measurements of $\mathrm{O}\left({ }^{3} \mathrm{P}\right)$ Doppler profiles from the photolysis of $\mathrm{NO}_{2}$ at $222.4 \mathrm{~nm}$ a translational temperature of $\sim 3000 \mathrm{~K}$ could be derived. The rate constant for the reaction of $\mathrm{O}\left({ }^{3} \mathrm{P}\right)$ with $\mathrm{H}_{2}$ for this temperature is 10 times less than the one for $\mathrm{O}\left({ }^{1} \mathrm{D}\right)$ reaction. ${ }^{38}$ Correcting the above calculations with this value, a $\mathrm{O}\left({ }^{1} \mathrm{D}\right)$ quantum yield for $\mathrm{NO}_{2}$ is derived which is only marginally smaller than the one given above. It is therefore assumed that the reaction of $\mathrm{O}\left({ }^{3} \mathrm{P}\right)$ can be neglected and in the further discussion a $\mathrm{O}\left({ }^{1} \mathrm{D}\right)$ quantum yield of $\phi_{0}\left({ }^{1} \mathrm{D}\right)\left(\mathrm{NO}_{2}\right)=0.45 \pm 0.06$ will be used. 


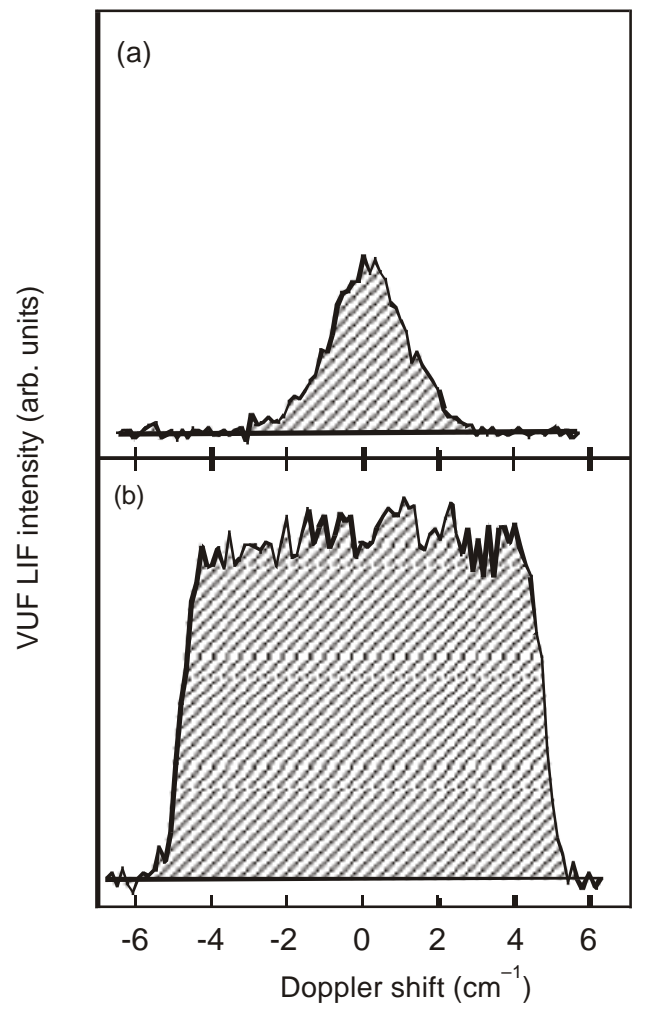

Figure 5. (a) Doppler profile of $\mathrm{H}$ atoms produced in the $\mathrm{O}\left({ }^{1} \mathrm{D}\right)+\mathrm{H}_{2}$ reaction measured after $300 \mathrm{~ns}$ (experimental conditions as in figure 4). (b) $\mathrm{H}$ atom Doppler profile measured in the $222.4 \mathrm{~nm}$ photolysis of $\mathrm{H}_{2} \mathrm{~S}$ (calibration) under collision-free conditions $\left(\mathrm{H}_{2} \mathrm{~S}\right.$ pressure $4 \mathrm{mTorr}$, pump-probe delay time $\left.100 \mathrm{~ns}\right)$. The centers of the Doppler profiles correspond to the $\left(2 p^{2} \mathrm{P} \leftarrow 1 s^{2} \mathrm{~S}\right)$ Lyman- $\alpha$ transition of the $\mathrm{H}$ atom $\left(82259 \mathrm{~cm}^{-1}\right)$.

In addition to the method described above, we carried out another set of independent measurements in which the $222.4 \mathrm{~nm}$ photolysis of $\mathrm{NO}_{2}$ ( 4 mTorr) was performed in the presence of a large excess of $\mathrm{N}_{2}$ ( 860 mTorr) to determine the time dependent increase of the initial $\mathrm{O}\left({ }^{3} \mathrm{P}\right)$ concentration due to additional $\mathrm{O}\left({ }^{3} \mathrm{P}\right)$ atoms formed by the quenching process of the $\mathrm{O}\left({ }^{1} \mathrm{D}\right)$ fragments by $\mathrm{N}_{2}$. It should be noted that monitoring the relative rise in a given $j$ level of $\mathrm{O}\left({ }^{3} \mathrm{P}\right)$ could give erroneous results due to the inter relaxation of different $j$ levels. Hence in the present work, the temporal profiles of $\mathrm{O}\left({ }^{3} \mathrm{P}_{j=2,1,0}\right)$ were taken individually under similar experimental conditions and summed up, after due correction of oscillator strength, to get the overall temporal profile of $\mathrm{O}\left({ }^{3} \mathrm{P}\right)$ up to $15 \mu \mathrm{s}$. In these studies the $\mathrm{O}\left({ }^{3} \mathrm{P}\right)$ quantum yield, $\phi_{\mathrm{O}}\left({ }^{3} \mathrm{P}\right)\left(\mathrm{NO}_{2}\right)=\left[\mathrm{O}\left({ }^{3} \mathrm{P}\right)\right] /\left[\mathrm{O}\left({ }^{3} \mathrm{P}\right)+\mathrm{O}\left({ }^{1} \mathrm{D}\right)\right]$, can be directly obtained by comparing the $\mathrm{O}\left({ }^{3} \mathrm{P}\right)$ concentrations measured right after the photolysis pulse with the $\mathrm{O}\left({ }^{3} \mathrm{P}\right)$ concentrations at delay times of $\sim 15 \mu$ at which all the $\mathrm{O}\left({ }^{1} \mathrm{D}\right)$ atoms produced in the $\mathrm{NO}_{2}$ photolysis are quenched to $\mathrm{O}\left({ }^{3} \mathrm{P}\right)$ atoms. The quantum yield of $\mathrm{O}\left({ }^{1} \mathrm{D}\right)$ obtained in this way was comparable to that obtained by the $\mathrm{O}\left({ }^{1} \mathrm{D}\right)+\mathrm{H}_{2}$ 
reaction method. The results of these two measurement, $\phi_{\mathrm{O}\left({ }^{1} \mathrm{D}\right)}\left(\mathrm{NO}_{2}\right)=0.45 \pm 0.06$, are in good agreement with the value of 0.44 obtained by fitting the results of Uselmann and Lee. ${ }^{37}$ Since $\mathrm{N}$ atom formation has been shown to be unimportant,${ }^{36}$ the quantum yield of $\mathrm{O}\left({ }^{3} \mathrm{P}\right)$ in the $222.4 \mathrm{~nm}$ photolysis of $\mathrm{NO}_{2}$ is $\phi_{\mathrm{O}}\left({ }^{3} \mathrm{P}\right)\left(\mathrm{NO}_{2}\right)=1-\phi_{\mathrm{O}\left({ }^{1} \mathrm{P}\right)}\left(\mathrm{NO}_{2}\right)=0.55$. The latter value was used in the present evaluation of the $\mathrm{O}\left({ }^{3} \mathrm{P}\right)$ quantum yield in the $222.4 \mathrm{~nm}$ photolysis of $\mathrm{SO}_{2}$ via (1), which resulted in an average value of $\Phi_{\mathrm{O}\left({ }^{3} \mathrm{P}\right)}=0 \cdot 13 \pm 0.05$. The quoted experimental error was calculated from the errors of the entries of (1) on the basis of simple error propagation.

\section{Discussion and conclusion}

The absolute $\mathrm{O}\left({ }^{3} \mathrm{P}\right)$ quantum yield $\Phi_{\mathrm{O}\left({ }^{3} \mathrm{P}\right)}=0.13 \pm 0.05$ of the present work can directly be compared with the result of the absolute fluorescence quantum yield measurements carried out by Hui and Rice for $\mathrm{SO}_{2}$ at room-temperature under bulb conditions. ${ }^{20}$ In the latter work, for the $222.4 \mathrm{~nm}$ wavelength which leads to a selective excitation of the highly structured $\tilde{C}^{1} \mathrm{~B}_{2}(1,2,2) \leftarrow \widetilde{X}^{1} \mathrm{~A}_{1}(0,0,0)$ vibronic band of $\mathrm{SO}_{2}$ a value of $\Phi_{f}=$ $0.845 \pm 0.127$ was derived. This value is in very good agreement with the $\mathrm{O}\left({ }^{3} \mathrm{P}\right)$ quantum yield obtained in the present study. Both results clearly demonstrate that appreciable amounts of $\mathrm{O}\left({ }^{3} \mathrm{P}\right)$ atoms are produced after photoexcitation of $\mathrm{SO}_{2}$ at room-temperature at $222.4 \mathrm{~nm}$. However, because the energy of a $222.4 \mathrm{~nm}$ laser photon $\left(44964 \mathrm{~cm}^{-1}\right)$ is lower than the $\mathrm{SO}_{2}\left(\tilde{C}^{1} \mathrm{~B}_{2}\right) \rightarrow \mathrm{SO}\left(X^{3} \Sigma^{-} ; v^{\prime \prime}=0\right)+\mathrm{O}\left({ }^{3} \mathrm{P}_{j=2}\right)$ dissociation threshold energy of $D_{0}=45725 \cdot 3(1) \mathrm{cm}^{-1}$ determined in ref. [23] only those $\mathrm{SO}_{2}$ ground-state parent molecules with a rotational energy, $E_{\text {rot }}$, higher than $D_{0}-\hbar \omega_{\text {pump }} \approx 761 \mathrm{~cm}^{-1}$ can actually be dissociated. Using the $\mathrm{SO}_{2}\left(\widetilde{X}^{1} \mathrm{~A}_{1}\right)$ ground-state molecular constants given in ref. [41] the fraction of room-temperature $\mathrm{SO}_{2}$ molecules with $E_{\mathrm{rot}}>761 \mathrm{~cm}^{-1}$ can be estimated to be about $0 \cdot 17 .{ }^{42}$ Comparison of this value with the $\mathrm{O}\left({ }^{3} \mathrm{P}\right)$ quantum yield measured in the present study shows that about $75 \%$ of the $\mathrm{SO}_{2}$ parent molecules with $E_{\mathrm{rot}}>761 \mathrm{~cm}^{-1}$ contribute to $\mathrm{O}\left({ }^{3} \mathrm{P}\right)$ atom formation suggesting that the initial $\mathrm{SO}_{2}$ rotational excitation plays an important role in the dissociation of the $\tilde{C}{ }^{1} \mathrm{~B}_{2}(1,2,2)$ vibronic level. The rovibrational dependence of the predissociation rate in the $\tilde{C}^{1} \mathrm{~B}_{2}$ state of $\mathrm{SO}_{2}$ was investigated by Ebata et al. ${ }^{21}$ In their LIF studies of $\mathrm{SO}_{2}$ at room-temperature they observed that for vibronic bands located at excitation energies higher than $45400 \mathrm{~cm}^{-1}$ the fluorescence lifetime of the bandheads (occurring at low rotational numbers) is significantly longer than that of the higher rotational levels (see table 2 of ref. [21]) indicating that high rotational levels are more predissociative than low levels. However, their final conclusion that predissociation occurs by curve crossing with the repulsive triplet state has to be questioned in the light of the recent results obtained by Becker et $a l,{ }^{22}$ who demonstrated that predissociation is caused by coupling to a bound potential surface which correlates with $\mathrm{SO}\left(X^{3} \Sigma^{-}\right)$and $\mathrm{O}\left({ }^{3} \mathrm{P}\right)$ products without a reaction barrier. The latter result is in agreement with the results reported in refs. [8, 14, 32] which clearly showed that photodissociation via the $\tilde{\widetilde{C}}{ }^{1} \mathrm{~B}_{2}$ state proceeds mainly through vibronic mixing between the $\tilde{C}{ }^{1} B_{2}$ state vibronic levels and the quasi-bound dissociation continuum of the $\widetilde{X}^{1} \mathrm{~A}_{1}$ ground-state. Hence it can be concluded that the $\mathrm{O}\left({ }^{3} \mathrm{P}\right)$ formation observed in the present study for $\mathrm{SO}_{2}$ at room-temperature is due to a similar mechanism in which the predissociation occurs, however, to a large extent via high rotational states of the optically prepared $\widetilde{C}{ }^{1} \mathrm{~B}_{2}(1,2,2)$ vibronic level. 


\section{Acknowledgments}

This work was partially supported by the Deutsche Forschungsgemeinschaft (DFG) via Sonderforschungsbereich (SFB) 359 'Reaktive Strömungen, Diffusion und Transport' at the University of Heidelberg. HPU and RKV acknowledge fellowships provided by the International Office of the DLR (Bonn, Germany) under the Indo-German bilateral agreement (project No. INI-207 and INI-050). RKV thanks Dr JP Mittal (Director, Chemistry and Isotope Group, BARC, Mumbai) for his continued interest in this joint programme. KSL thanks KAIST for supporting his stay at Physical Chemistry Institute in Heidelberg. HRV would like to thank Prof. J Wolfrum (Director of the Institute of Physical Chemistry, University Heidelberg) for his continuous support.

\section{References}

1. Georgii H W and Warneck P 1999 in Global aspects of atmospheric chemistry (ed.) R Zellner (Springer: Berlin), and references therein

2. Ploch H J and Troe J 1984 J. Chem. Kinet. 16 1531, and references therein

3. Jackson W M and Okabe H 1986 Advan. Photochem. 1317

4. Okabe H 1978 The photochemistry of small molecules (New York: Wiley)

5. Dastageer A, Hegazi E, Hamadan A and Al-Adel F 1999 J. Chem. Phys. 1111784

6. Ray P C, Arendt M F and Butler L J 1998 J. Chem. Phys. 109 5221, and references therein

7. Brand J C D, Chiu P H, Hoy A R and Bist H D 1976 J. Mol. Spectros. 6043

8. Katagiri H, Sako T, Hishikawa A, Yazaki T, Onda K, Yamanouchi K and Yoshino K 1997 J. Mol. Struct. 413 589, and references therein

9. Freedman A, Yang S C and Bersohn R 1979 J. Chem. Phys. 705313

10. Kawasaki M, Kasatani K, Sato H, Shinoha H and Nishi N 1982 Chem. Phys. 73377

11. Kawasaki M and Sato H 1987 Chem. Phys. Lett. 139585

12. Felder P, Effenhauser C S, Haas B M and Huber J R 1988 Chem. Phys. Lett. 148417

13. Felder P, Hass B-M and Huber J R 1993 Chem. Phys. Lett. 204248

14. Kanamori H, Butler J E, Kawaguchi K, Yamada C and Hirota E 1985 J. Chem. Phys. 83611

15. Chen X, Asmar F, Wang H and Weiner B R 1991 J. Phys. Chem. 956415

16. Hansen N, Andresen U, Dreizler H, Grabow J U, Mader H and Temps F 1998 Chem. Phys. Lett. 289311

17. Huang Y-L and Gordon R J 1990 J. Chem. Phys. 93868

18. Abe M, Sato Y, Inagaki Y, Matsumi Y and Kawasaki M 1994 J. Chem. Phys. 1015647

19. Okabe H 1971 J. Am. Chem. Soc. 937095

20. Hui M-H and Rice S A 1972 Chem. Phys. Lett. 17474

21. Ebata T, Nakazawa O and Ito M 1988 Chem. Phys. Lett. 14331

22. Ivanco M, Hager J, Sharfin W and Wallace S C 1983 J. Chem. Phys. 786531

23. Becker S, Braatz C, Linder J and Tiemann E 1995 Chem. Phys. 196275

24. Braatz C and Tiemann E 1998 Chem. Phys. 22993

25. Ebert V, Schulz C, Volpp H-R, Wolfrum J and Monkhouse P 1999 Isr. J. Chem. 391

26. Brownsword R A, Hillenkamp M, Laurent T, Vatsa R K and Volpp H-R 1997 J. Chem. Phys. 1064436

27. Armandillio E, Luches A, Nassisi V and Perrone M R 1985 Appl. Opt. 2418

28. Decker M and Sick V 1996 Appl. Opt. 35482

29. Radzig A A and Smirnov B M 1985 Reference data on atoms, molecules and ions (Springer: Heidelberg)

30. Levine R D and Bernstein R B 1987 Molecular reaction dynamics and chemical reactivity (Oxford: University Press)

31. (a) Röth E-P, Runke R, Moortgat G, Meller R and Schneider W UV/VIS-Absorption cross sections and quantum yields for use in photochemistry and atmospheric modeling, Part 1: Inorganic substances, Berichte des Forschungszentrums Jülich; Nr. 3340 (ISSN 0944-2952), Jülich, Germany; (b) Bass A M, Ledford A E and Lauffer A 1976 J. Res. Natl. Bur. Stand. A80 143 
32. Troe J 1983 J. Chem. Phys. 796017

33. Robra U, Zacharias H and Welge K H 1990 Z. Phys. D. 16175

34. Rubahn H G, van der Zande W J, Zhang R, Bronikowski M J and Zare R N 1991 Chem. Phys. Lett. 186154

35. Reid S A and Reisler H 1994 J. Chem. Phys. 1015683

36. Preston K F and Cvetanovic R J 1966 J. Chem. Phys. 452888

37. Uselman W M and Lee E K C1976 J. Chem. Phys. 651948

38. DeMore W B, Sander S P, Golden D M., Hampson R F, Kurylo M J, Howard C J, Ravishankara A R, Kolb C E and Molina M J 1992 Chemical kinetics and photochemical data for use in stratosphere modeling, No. 10, NASA, JPL Publication 92-20. For reaction 3 the latest value reported by R F Curl et al (Chem. Phys. Lett. 337 (2001) 72) is (1.5 $\pm 0 \cdot 3) \times$ $10^{-10} \mathrm{~cm}^{3}$ molecule $\mathrm{s}^{-1}$

39. Brownsword R A, Hillenkamp M, Volpp H-R and Vatsa R K 1999 Res. Chem. Intermed.25 339

40. Koppe S, Laurent T, Naik P D, Volpp H-R, Wolfrum J, Arusi-Parpar T, Bar I and Rosenwaks S 1993 Chem. Phys. Lett. 214546

41. Herzberg G 1960 Electronic spectra and electronic structure of polyatomic molecule (Van Nostrand: Princeton)

42. For details, see chapter I-4.3. of ref. 4 